\title{
The Blurring of Identity: Cochlear Implants and the Deaf Community
}

\author{
Zoé Bernicchia-Freeman
}

When American otologist William House invented the first cochlear implant in 1961, the hearing world rejoiced. Since then, implantation rates have steadily increased. As of five years ago, over 324,200 devices have been implanted worldwide (U.S. Department of Health \& Human Services 2017). However, the invention and implementation of the cochlear implant have been very controversial in a group of deaf individuals known as the Deaf community. While the hearing world commonly views deafness as a handicap, this community considers it to be an enriching perspective on life. Moreover, the Deaf community celebrates their deafness. The cochlear implant conflicts with Deaf pride, which does not view deafness as something that needs to be "fixed."

A cochlear implant is a device that receives sound stimuli from the outside world and transmits it to the auditory nerve. It is composed of an external part (the speech processor and the transmitter) and an internal part (the implant). The speech processor sits on the outside of the head and uses small microphones to pick up sound. These sounds are then coded into signals by the processor and are sent to the transmitter, which is clipped onto the back of the ear. The transmitter sends the signals through the skin 
to the implant, which converts them into electrical energy and stimulates nerve fibres in the cochlea. Once this process is complete, the brain can recognizes the signals as sound (Cochlear Australia and New Zealand 2014). Cochlear implants do not restore regular hearing via the ear. Unlike standard hearing aids, they bypass the ear altogether and send sound signals directly to the brain (U.S. Department of Health \& Human Services 2017). As a result, cochlear implants provide an electronic perception of sound that can be significantly different from regular hearing - patients often report that it takes years to adapt to the electronic feedback after their initial surgery, and as a result they have difficulty following group conversations and speaking on the telephone (Punch and Hyde 482-483). However, cochlear implants are celebrated in the scientific community because they allow deaf individuals to actually perceive sound, regardless of the quality of the sound.

Some proud members of the Deaf community believe that the cochlear implant is an attack on Deaf culture. On the other hand, members of the hearing world view the device as an opportunity for deaf individuals to overcome their "disability." Irma Munoz-Baell and M. Teresa Ruiz summarize the crux of this debate: "two opposing perspectives of conceptualising deafness in contemporary society have been reported and discussed in scientific literature. The first one defines deafness as a pathological condition, while the second one regards deafness as a cultural identifier" (40). As a hearing individual who has been involved in the Deaf community, I have been exposed to both perspectives, and I take no side in this debate. Therefore, this work will not evaluate whether or not the device should be used; instead, it seeks to explore the impact of the device on the Deaf community and on the construction of Deaf identity. Literature will be drawn from various disciplines, including otology, psychology, Deaf culture, hearing culture, disability studies, and ethics. By integrating ideas from these disciplines, this work aims to provide a two-pronged investigation of the cochlear implant debate. First, I will evaluate the historical roots contributing to the controversy of the debate by examining reasoning behind hearing and Deaf perspectives. Second, I will explore how cochlear implants are affecting Deaf youth. By giving deaf children and their parents the power to choose between the hearing world and the Deaf world, cochlear implants are blurring the picture of the typical Deaf identity. This topic is of great importance because the future of the Deaf community lies in the hands of these families. Therefore, it is crucial to track the social and psychological repercussions of cochlear implants as implantation rates continue to rise. The goal of this work is to investigate these repercussions and provide a fair evaluation for both sides of the cochlear implant debate. According to various global studies conducted in 2010, approximately 360 million individuals live with "disabling hearing loss" (World Health Organization 2018). However, it is important to note that this work will focus solely on deafness and Deaf culture in the Western world, as perceptions of deafness differ in developing areas (Penn et al. 131).

The first section of this paper will explore the historical roots of Deaf pride. This will provide insight into the Deaf perspective, and will help answer the following question: why are members of the Deaf community so opposed to cochlear implants?

Pride and identity are fundamental values of Deaf culture, and many academics insist that these values have been shaped by the community's history of oppression. According to Paddy Ladd and Harlan Lane, this oppression can be compared to that of ethnic minorities. In their work "Deaf Ethnicity, Deafhood, and Their Relationship," they write the following:

As with ethnic groups, much of [Deaf history] concerns oppression...In the beginning, we were dispersed and isolated, but then our people gathered and built our institutions; there was a Golden Age in which we flourished, followed by the dark ages of oppres- 
sion; but we rose up victorious and recovered our lost values and prestige. (567)

According to Ladd and Lane, the Deaf community is currently living out their "Golden Age": Deaf individuals finally have equal rights, are entitled to special education, and are free to communicate using manual language (World Federation for the Deaf 2011). Due to these newfound freedoms, elements of Deaf culture that were once repressed are now stronger than ever, and the Deaf community is driven by pride. "Being Deaf and allegiance to the group" is valued within Deaf culture (Ladd and Lane 566). Therefore, deafness is actually viewed in a positive light, and self-acceptance is crucial. Many believe that the rise of cochlear implants is jeopardizing this view. By implying that deaf individuals should be "fixed," the implementation of the device contradicts the acceptance of deafness and further handicaps the community (Gauntlett $850)$.

The Deaf community's journey towards acceptance has been long and arduous. For thousands of years, they were alienated or forced to conform to hearing norms. Therefore, the increase in cochlear implantation raises concerns that the community's progress is being reversed. In "A History of Unequal Treatment: The Qualifications of Handicapped Persons as a 'Suspect Class' under the Equal Protection Clause," Marcia Pearce Burgdorf and Robert Burgdorf Jr. describe the past oppression of the deaf in educational institutions:

Any person who deviated from the norms of what was expected of a pupil... was viewed as disruptive and burdensome and thus not suited for classroom instruction. ... The result of this exclusion... was the removal of any incentive for educators to develop programs suited to the needs of such children.... It was not until the 1860's that public school special education classes for deaf children were initiated in [America]. (855)

Instead of making the education system accessible to all, students were excluded. The exclusion of deaf students placed the burden to adapt on the marginalized individuals rather than on the institutions. Links can be drawn between this past oppression and the impacts of cochlear implants today. Instead of enforcing the education of sign language, deaf people are encouraged to adapt to the hearing world by undergoing invasive surgery and speech therapy (Sparrow 144).

Discriminatory practices in education pale in comparison to the abhorrent treatment of deaf people dating back thousands of years. Burgdorf and Burgdorf write the following: "In Sparta, around 800 B.C., mentally and physically defective children were left on mountainsides or in pits to fend for themselves. Even enlightened Athenians put deaf children to death" (883). This cruel behaviour was approved by some of the most influential figures of the era, including Plato and Aristotle (M. Burgdorf and R. Burgdorf 884). In 355 B.C., Aristotle declared that "Those who are born deaf become senseless and incapable of reason" (Gallaudet University Press). These beliefs and practices remained prominent throughout the Middle Ages, when non-conforming individuals were either imprisoned or exiled from cities (M. Burgdorf and R. Burgdorf 884). It wasn't until the mid 16th century that Aristotle's beliefs were challenged. Physician Girolamo Cardano was the first documented individual to recognize the reasoning abilities of the deaf (Estonian Deaf Union 2010).

In his article "The Evolving Ethics of Cochlear Implants in Children," John Lantos explains the two forms of education available to deaf children: manualism and oralism. Supporters of manualism believe that deaf children should learn sign language, while supporters of oralism believe that they should learn to speak and read lips. While many academics argue that a combination of manualism and oralism is optimal for a deaf child's development, extreme oralists (like Alexander Graham Bell) were opposed to the teaching of sign language (Lantos 
323). Supported by other well-known oralists and influenced by the ideas of social Darwinism, Alexander Graham Bell promoted the eugenics movement. He believed that deaf individuals could not contribute to society and even went so far as to encourage a ban on deaf-deaf marriages in order to eliminate deaf individuals from the gene pool (Lantos 323). In "Upon the formation of a deaf variety of the human race," Bell writes that "the production of a defective race of human beings would be a great calamity to the world" (217). While he himself was fluent in sign language, Bell believed that deaf children should learn to adapt to the hearing world instead of learning their own language. He suggested that sign language education encouraged inter-deaf marriage, which only perpetuated the "calamity" of deafness. According to Lantos, this history of oppression created a fear of oralism and can explain the Deaf community's response to the invention of cochlear implants: "They saw implants as a return to the philosophy of oralism and a rejection of sign language." (324).

Oralism is arguably the Deaf community's greatest adversary because it defines language as speech (Bauman 242). In her 1999 work Lend Me Your Ear, Brenda Bruggemann explores the perception of deafness: "Language is human; speech is language; therefore deaf people are inhuman and deafness is a problem" (11). Much like the exclusion of deaf children in schools, oralism supports the idea that the "disabled" Deaf community should adapt to the hearing world. However, when pondering disability as a concept, many academics reach the conclusion that it is merely a cultural construct (Branson and Miller 3). In Damned for Their Difference: The Cultural Construction of Deaf People as Disabled, Jan Branson and Don Miller write the following:

In a Deaf community, a hearing person who cannot sign is disabled, handicapped... Conditions categorized in our society as petit mal epilepsy, autism, and blindness may be associated in another so- ciety with intense spirituality and accepted as evidence of superiority. Appearances and behaviors are interpreted within cultural contexts. "The disabled" are not a natural but a cultural construction. (Preface xi)

Following Branson and Miller's logic, cochlear implants could be perpetuating these interpretations by encouraging the deaf to be more like hearing people. This reinforces the construction of the Deaf identity as inferior.

Ladd and Lane's comparison of deaf experience to the oppression of ethnic minorities allows for significant connections to be drawn between works on Deaf identity and the construction of difference. In Frantz Fanon's work Black Skin White Masks, he writes: "I came into the world imbued with the will to find a meaning in things, my spirit filled with the desire to attain the source of the world, and then I found that I was an object in the midst of other objects" (82). While Fanon is referencing race in his work, his thoughts on the "inferiority complex" can be similarly applied to the inferiority imposed upon the Deaf community. When born into deaf families, it is natural for deaf children to initially assume that deafness is the norm. If surrounded by a rich community, they are raised in the centre of Deaf culture. It is only once they venture out into the hearing world that they discover the drawbacks of their "condition" (Sparrow 138). When words like "disabled" and "handicapped" are used to describe deaf children, inferiority is forced upon them, and they are not free to discover their own identities. Approximately 90\% of all deaf children are born into hearing families, so this inferiority complex begins at birth (U.S. Department of Health \& Human Services 2016).

Now that we have gained some historical insight on the Deaf perspective, we can turn our attention towards ongoing implications of cochlear implants. The following section will explore the effects of the device on youth, their parents, Deaf identity, and the future of the Deaf community.

There are two categories of hearing loss in children: congenital and acquired. Congeni- 
tal hearing loss is present at birth and can be the result of premature births, birth complications, maternal infections, maternal drug abuse, genetic factors, and more. Acquired hearing loss is developed throughout childhood and can be caused by postpartum infections and diseases, injuries, loud noise exposure, perforated eardrums, and other traumatic events (Healthy Hearing 2017). This myriad of factors indicates that hearing loss in youth is not uncommon. Consequently, many children are candidates for cochlear implant surgery.

By the year 2000, American children as young as 12 months of age began receiving implants (U.S. Department of Health \& Human Services 2017). This is a critical age for development. According to the Ontario Ministry of Children and Youth Services, the most critical time for a child to cultivate language and communication skills is under the age of three (2016). Therefore, parents are rushed to make life-altering decisions regarding the future identities of their deaf children.

In his work "Cochlear implants, the Deaf culture, and ethics: A study of disability, informed surrogate consent, and ethnocide," Glenn Hladek explores the complexities of these decisions by questioning the rights of parents to determine their child's identity. While parental versus state rights in life-threatening scenarios are heavily discussed in medical literature, Hladek writes that "the debate directed toward non-life threatening conditions... is either assumed (parental authority) or paternalistic (medical or court authority), and provides little guidance for moral analyses of the question of not only who decides, but also how they decide" (31). If the parents are hearing, the Deaf community finds parental authority regarding cochlear implantation problematic. They believe that the parents lack perspective and are most likely unaware of the existence of the Deaf community. Therefore, "a hearing person's interest conflicts with the deaf child's best interest" (Hladek 38). A main concern for the community is that deaf children will grow up with implants, and will never bother to learn sign language since they can experience sound. This limits their future interactions with the Deaf community and deprives them from the benefits of learning sign language (Mellon et al. 171).

According to Hladek, the community understands that these decisions can ultimately only be made by parents. Nonetheless, it is crucial that parents are made aware of the Deaf perspective (Hladek 38). The community suggests that there should be a Deaf adult acting as a third party, in order to offer parents this perspective. Regarding "proxy consent," Hladek states that there is legal precedent for the involvement of a disinterested third party when decisions must be made on behalf of "non-competent" individuals (38). However, it is important to keep in mind that this third party would be biased and would advocate for the Deaf community, most likely opposing the implantation (Hladek 39).

The Deaf community is one that individuals are born into, and whether or not they embrace the culture, all individuals with hearing loss have the lifelong potential to join the group. Therefore, the community considers every deaf newborn as part of their family (Hladek 42). While these values are supportive and inclusive, Hladek further explores the complexity of this issue by presenting an alternative idea: "Each deaf child is considered a means to the culture's ends, that is survival of the culture, not the child's own end. The deaf child exists to fulfil the culture's hopes and dreams, not necessarily the child's hopes and dreams" (42). Due to the rise of cochlear implants, "ethnocide" has become a concern for Deaf culture. Hladek states that the community may be valuing the survival of its culture over the wellbeing of its individuals (42). This is problematic to academics like Dena Davis, who writes in "Genetic Dilemmas and the Child's Right to an Open Future" that "the autonomy of the individual is ethically prior to the autonomy of the group" (11).

Links can be drawn between Hladek's observations and acclaimed philosophical theories put forth by William A. Galston and John Stuart Mill. In his work "Two Concepts of Liberalism", 
Galston writes that "the liberty not to be coerced into, or trapped within, ways of life" must be defended (522). With respect to the issue of cochlear implants in youth, this logic could be used to argue that failing to implant a child would be trapping them within the Deaf community. Not all deaf individuals decide to identify as culturally Deaf, and these children could miss out on the opportunity to be raised in the hearing world. Furthermore, Mill vouches for individual liberty and argues that having a multitude of options available produces the best outcome for any individual. In On Liberty, he writes:

But different persons also require different conditions for their spiritual development; and can no more exist healthily in the same moral, than all the variety of plants can in the same physical, atmosphere and climate. The same things which are helps to one person towards the cultivation of his higher nature are hindrances to another... Such are the differences among human beings... unless there is a corresponding diversity in their modes of life, they neither obtain their fair share of happiness, nor grow up to the mental, moral, and aesthetic stature of which their nature is capable. (63)

According to Galston and Mill, the optimal scenario would be one where a deaf child grows up with as many options as possible and is not limited to either of the two worlds. Therefore, why not just let children grow up without implants, immerse them within the Deaf community, and let them make their own decision about the implant once they have acquired the Deaf perspective? This could resolve the controversy of parental choice and let children choose their own identities. Unfortunately, the reality is not so simple. Much of the audiological literature states that the earlier a child receives an implant, the better chance they have of adapting successfully to the device (Marschark 214). Therefore, waiting for children to age and make their own decisions could unintentionally limit them to the Deaf world. By blurring the typical image of the Deaf identity and introducing all of these complexities, the rise of cochlear implantation is influencing the future livelihood of the Deaf community and its culture.

Once a child receives an implant, it is crucial to track their social development. How is their identity affected as they age? Renée Punch and Merv Hyde studied the social participation of children and adolescents with cochlear implants by conducting interviews with the children, their parents, and their teachers. Their goal was to evaluate the psychosocial factors affecting youth with implants. Fifty individuals were interviewed, and the results across the three groups "displayed commonalities" (Punch and Hyde 474). Punch and Hyde published a summary paper of their research, including key quotations from select interviews and the following overview of their results:

Some children had little contact with other deaf children (with or without cochlear implants) despite parents and teachers perceiving such contact beneficial. Children attending schools where there were other deaf children valued friendships with both deaf and hearing peers. Adolescence was a particularly difficult time for some as they struggled with feelings of self-consciousness about their deafness and external cochlear implant equipment and worries around friendships, dating, and their future place in the world. (474)

One mother said that her daughters, who both received implants when they were toddlers, were very social children. However, they began to experience difficulties interacting with their peers as they grew. The mother's reasoning for this change in behaviour was that as girls age, they begin to "talk a lot more and play less" (Punch and Hyde 481). Despite having received the im- 
plants nearly a decade earlier, the young girls had difficulties with oral communication as they approached the age of ten. Other parents reported that their children had difficulties using telephones, even though the children had received implants at a very young age (Punch and Hyde 482). This illustrates that cochlear implants do not "fix" deafness, which is a common misconception. As I explained at the very beginning of this paper, cochlear implants do not restore regular hearing. A deaf person with a cochlear implant is still technically deaf because they have not regained the physical ability to hear with their ears. This is what allows adult Deaf individuals with implants to remain active in the community and continue to identify as culturally Deaf. However, if an individual with a successful implant chooses not to be involved in the community and does not use sign language to communicate, they could consider themselves hearing instead. Rupert Gauntlett argues that there also exists a scenario where cochlear implantation could result in a lack of identity altogether. In "Cochlear implantation is controversial among deaf people," Gauntlett writes that "children with cochlear implants will fall into the group who are neither deaf nor hearing, unable to be fully integrated into a hearing world but set apart from the vibrant culture of deaf people" (850). Therefore, an individual with a cochlear implant could identify as hearing, Deaf, or neither. These technicalities make the discovery and assertion of one's identity even more challenging and could partly explain the conclusions drawn from Punch and Hyde's interviews with adolescents. The rise of cochlear implants has caused identity in the Deaf community to become fluid - as children grow into teenagers, they begin to question their identities as semiDeaf and semi-hearing individuals.

Punch and Hyde wrote that some participants treasured friendships with both deaf and hearing peers (474). It is therefore possible for the cultures to merge successfully, thus improving the lives of these children by expanding their social circles. However, in order to rem- edy the barriers between both communities, we must first overcome our "narrative of disability" (Crouch 16). This narrative encourages hearing people to view themselves as superior to the deaf. In response, the Deaf community argues that they are unique - not inferior. When attempting to break down these barriers, the community is often faced with "audism". The term "audism" was coined by Tom Humphries in 1975 and refers to "discrimination against the deaf" (Bauman 239).

According to Richard Eckert and Amy Rowley, audism is a unique kind of discrimination that manifests itself in different forms: "overt audism", "covert audism", and "aversive audism" (108). Any policies or practices that actively exclude deaf individuals are considered overt audism, whereas instances when discriminatory behaviour is hidden or concealed are considered covert audism. Aversive audism, on the other hand, is the unintentional denial of discriminatory behaviour. Eckert and Rowley state that an aversive audist may romanticize Deaf culture while maintaining the belief that all deaf individuals wish to be "assimilated" into the hearing world (109). Some members of the Deaf community view the creation of the cochlear implant as a manifestation of aversive audism, because while it was created to do "good", it was also created with the intention of making deaf people "normal." This implies that deafness is a problem in the first place, and that hearing people are taking it upon themselves to "fix" it, which can be perceived as condescending notions of supremacy.

Audism is directly linked to the inferiority complex discussed in the previous section, and further perpetuates the societal construction of deaf disability. It affects how the hearing world perceives the deaf, which in turn impacts how the deaf perceive themselves. According to Eckert and Rowley, the deaf and hearing worlds will not be able to achieve integration until this audistic mentality is eradicated (124). Unfortunately, this will not occur as long as these two worlds remain opposing forces. To achieve true integra- 
tion, barriers between the communities must be dissolved, and differences between the deaf and the hearing should be celebrated. While their abilities differ, their potential to communicate and learn is equal; deafness is not a learning disability. Regarding the debate between oral and signed language, Robert A. Crouch writes that "the deaf child no less than the hearing child has all the requisite skills that will enable her to achieve a different, but no less human, expressive potential" (18). Each community is rich in its own unique way and neither community is superior.

A deaf teenager interviewed by Punch and Hyde discussed her ability to interact with both hearing and deaf peers at school. Her school had a support system in place for deaf students and the communities were encouraged to mix: "my deaf friends sign, my hearing friends talk to me" (485). In another interview, a mother described the impact that meeting other implanted children had on her son: "and he suddenly realized there were. . . other kids his age... with the implant... and I think that it was a bit more accepting for him" (484). When a child with an implant is given the proper support, the results can be beneficial and rewarding. Therefore, in an attempt to step away from the dichotomy of deaf versus hearing, I propose that we focus on a third possible identity: deaf youth with cochlear implants. As implantation rates continue to rise, the number of deaf children growing up with the device will rise as well. Why not build a community where deaf children with implants can unite, instead of having to choose between both worlds? This third community could begin to bridge the gap between the deaf and the hearing. I have met deaf children with implants, and while they are grateful for the opportunity to perceive sound, the majority of them struggle with asserting their identity. In this environment, youth with implants could learn about the Deaf community while still being members of the hearing world. They would be free to discover their own identities and explore the many opportunities offered by both cultures.

A cochlear implant is merely an object, which, in itself does not challenge the different ways in which its users choose to identify. It is not the device, but its implementation that is problematic. By being viewed as a way to "fix" the deaf, the implant is driving the two communities even further apart. I have met Deaf individuals who have told me that they would never receive a cochlear implant, because they see the device as a betrayal against their culture and identity. Further, these individuals feel betrayed by other members of the Deaf community who choose to receive the implant. Therefore, the audistic mentality behind the device is driving individuals within the community apart as well.

In conclusion, it is clear that cochlear implants are here to stay. In fact, as you read this paper, audiologists and innovators around the world are developing and refining the latest cochlear model. Fighting the use of the device is counterproductive; statistics suggest that its implantation rates will continue to rise, regardless of its social implications (U.S. Department of Health \& Human Services 2017). Therefore, whether the technology is embraced or not, it is the mentality behind its creation and implementation which must be changed. Cochlear implants should be used to increase communication between the deaf and the hearing by allowing deaf individuals to overcome barriers in the "abled" world we inhabit today. However, cochlear implants should only be employed to facilitate meaningful interactions between both worlds - they should not be seen as a reparative measure to "cure disability." We have seen throughout history that this mentality is extremely harmful to the Deaf community. Moreover, if we are successful in changing this mentality, cochlear implants could actually help the Deaf community combat audism by finally giving them a platform to spread awareness in the hearing world. 


\begin{abstract}
About the Author
I am currently a student in the Arts \& Science program at McMaster University, and I am hoping to pursue a Combined Honours degree in History. My research interests (other than History) include Bioethics, Philosophy, Physics, Literature, and Linguistics. When I started studying American Sign Language, I had no idea that I would be exposed to such an incredibly rich and beautiful culture. Over the past year, I've been mentored by members of the Deaf community, and it has been a very eye-opening experience. Being exposed to Deaf perspectives has made me question how I view the world, and has made me redefine my own interpretation of "disability". I decided to write this paper because I found the cochlear implant debate fascinating, but also because I wanted to raise awareness. If anything, I hope that this piece sparks discussion on the subject. The lack of awareness regarding deafness in the hearing world is astounding. Deaf issues deserve a platform in the hearing world, now more than ever.
\end{abstract}


Works Cited

Bauman, Dirksen. "Exploring the Metaphysics of Oppression." The Journal of Deaf Studies and Deaf Education, vol. 9, no. 2, 2004, pp. 239-246. Oxford Academic, doi:10.1093/deafed/enh025. Accessed 27 November 2016.

Bell, Alexander G. "Upon the formation of a deaf variety of the human race." Memoirs of the National Academy of Sciences, vol. 2, no. 275, 1884, pp. 179-224.

Branson, Jan, and Don Miller. Damned for Their Difference: The Cultural Construction of Deaf People as Disabled. Gallaudet University Press, 2002.

Bruggemann, Brenda. Lend Me Your Ear. Gallaudet University Press, 1999.

Burgdorf, Marcia Pearce, and Robert Burgdorf Jr. "A History of Unequal Treatment: The Qualifications of Handicapped Persons as a 'Suspect Class' under the Equal Protection Clause." Santa Clara Law Review, vol. 15, no. 4, 1975, pp. 855- 910. Retrieved from http://network.bepress.co $\mathrm{m} /$ law/. Accessed 22 November 2017.

"Cochlear implants-how do they work?" YouTube, uploaded by Cochlear Australia and New Zealand, 24 Nov 2014, www.youtube.com/watch?v=p4C5O_OgR0s.

Crouch, Robert A. "Letting the deaf Be Deaf: Reconsidering the use of Cochlear Implants in Prelingually Deaf Children." Hastings Center Report, vol. 27, no. 4, 1997, pp. 14-21. National Center for Biotechnology Information, PubMed PMID:9271717. Accessed 26 November 2017.

Davis, Dena. "Genetic dilemmas and the childs right to an open future." Hastings Center Report, vol. 27, no. 2, 1997, pp. 7-15. National Center for Biotechnology Information, PubMed PMID:9131346. Accessed 26 November 2017.

Eckert, Richard, and Amy Rowley. "Audism: A Theory and Practice of Audiocentric Privilege." Humanity 83 Society, vol. 37, no. 2, 2013, pp. 101-130. Sage Journals, doi:10.1177/01605976134 81731. Accessed 28 November 2017.

Fanon, Frantz. Black Skin White Masks. Translated by Charles Lam Markmann, Pluto Press, 1986.

Galston, William A. "Two Concepts of Liberalism" Ethics, vol. 105, no. 3, 1995, pp. 516-534. JSTOR, http://www.jstor.org/stable/2382140. Accessed 28 November 2017.

Gannon, Jack R. "Deaf Heritage: A Narrative History of Deaf America." Gallaudet University Press, 1981, http://gupress.gallaudet.edu/excerpts/DHintro.html. Accessed 23 November 2017.

Gauntlett, Rupert. "Cochlear Implantation Is Controversial Among Deaf People." British Medical Journal, vol. 312, no. 7034, 1996, p. 850. JSTOR, http://www.jstor.org/stable/29731200. Accessed 22 October 2017.

"Hearing Evaluation in Children." KidsHealth, Mar. 2016, https://goo.gl/R6qTSq. Accessed 23 October 2017.

Hladek, Glenn A. "Cochlear implants, the Deaf culture, and ethics: A study of disability, informed surrogate consent, and ethnocide." Monash Bioethics Review, vol. 21, no. 1, 2002, pp. 2944. National Center for Biotechnology Information, PubMed PMID:15828157. Accessed 2 December 2017.

"Human Rights: How to understand deaf rights?" World Federation of the Deaf, 7 Jan. 2011, https://wfdeaf.org/human-rights/. Accessed 22 November 2017. 
Hyde, Merv, and Renée Punch. "Social Participation of Children and Adolescents with Cochlear Implants: A Qualitative Analysis of Parent, Teacher, and Child Interviews." Journal of Deaf Studies and Deaf Education, vol. 16, no. 4, 2011, pp. 474-493. National Center for Biotechnology Information, doi: 10.1093/enr001. Accessed 23 October 2017.

Ladd, Paddy, and Harlan Lane. "Deaf Ethnicity, Deafhood, and Their Relationship." Sign Language Studies, vol. 13, no. 4, 2013, pp. 565-579. Project Muse, doi:10.1353/sls.2013.0012. Accessed 22 November 2017.

Lantos, John D. "The Evolving Ethics of Cochlear Implants in Children." Ethics for the pediatrician, vol. 33, no. 7, 2012, pp. 323-326. National Center for Biotechnology Information, doi: 10.1542/pir.33-7-323. Accessed 22 October 2017.

Marschark, Marc. "Consensus on Cochlear Implants?" Journal of Deaf Studies and Deaf Education, vol. 1, no. 3, 1996, pp. 213-214. JSTOR, doi:10.1093/a014296. Accessed 22 October 2017.

Mellon, Nancy, et al. "Should All Deaf Children Learn Sign Language?" Pediatrics, vol. 136, no. 1, 2015, pp. 170-176. National Center for Biotechnology Information, PubMed PMID:26077481. Accessed 28 November 2017.

Mill, John S. On Liberty. Batoche Books, 1859.

Mroz, Mandy. "Hearing loss in children" Healthy Hearing, 4 May 2017, https://www.healthyhearing. com/help/hearing-loss/children. Accessed 4 December 2017.

Munoz-Baell, Irma, and M. Teresa Ruiz. "Empowering the Deaf. Let the Deaf be Deaf." Journal of Epidemiology and Community Health, vol. 54, no. 1, 2000, pp. 40-22. JSTOR, www.jstor.org/stable/25569121. Accessed 6 April 2018.

Penn, Claire, et al. "Deaf-Hearing Interchange in South Africa." Sign Language Studies, vol. 71, 1991, pp. 131-142. JSTOR, www.jstor.org/stable/26204725. Accessed 6 April 2018.

"Prevention of Blindness and Deafness: Estimates." World Health Organization, April 2013, http://w ww.who.int/pbd/deafness/estimates/en/. Accessed 29 April 2018.

"Quick Statistics About Hearing" U.S. Department of Health E3 Human Services, 15 Dec. 2016, https://www.nidcd.nih.gov/health/statistics/quick-statistics-hearing. Accessed 22 November 2017.

Sparrow, Robert. "Implant and ethnocide: learning from the cochlear implant controversy." Disability \& Society, vol. 25, no. 4, 2010, pp. 455-466. Taylor \& Francis online, doi: 10.1080/09687591003755849.Accessed 22 November 2017.

"Timeline: History of the Deaf community." Estonian Deaf Union, 16 June 2010, http://www.ead.ee/ foreign_deaf_history. Accessed 25 November 2017.

"What is a cochlear implant?" U.S. Department of Health \& Human Services, 6 Mar. 2017, https://www.nidcd.nih.gov/health/cochlear-implants\#a. Accessed 21 October 2017.

"Your baby's speech and language skills from birth to 30 months." Ministry of Children and Youth Services, 12 May 2016, https://goo.gl/9xtYNH. Accessed 21 October 2017. 